\title{
Is the climate emergency editorial relevant to surgeons?
}

\author{
Jayaindra Fernando \\ The Lanka Hospitals, Sri Lanka
}

\begin{abstract}
Keywords: Climate change; carbon footprint; greenhouse gases; GHG; surgical services

\section{Introduction}

The sequence of anthropogenic greenhouse gas (GHG) emissions causing climate change is now universally accepted[1]. To highlight the urgent need to reverse climate change, editors of 231 leading international medical journals[2] published a common climate emergency editorial[3] in their September 2021 issues. The signatory journals include those with a widespread reach as well as surgical journals.
\end{abstract}

The eminent editors set the tone of the editorial at the outset, when they state that "health is already being harmed by global temperature increases and the destruction of the natural world, a state of affairs health professionals have been bringing attention to for decades. The science is unequivocal; a global increase of $1.5^{\circ} \mathrm{C}$ above the pre-industrial average and the continued loss of biodiversity risk catastrophic harm to health that will be impossible to reverse"[3]. This article attempts to draw the relevance of this unprecedented editorial and the climate change discussion to surgical practice.

\section{Global climate change discussion}

The first assessment report (FAR) of the IPCC[4] in 1990 warned that "major health impacts are possible" which three decades on seem to have been proven correct. Later publications by the IPCC including AR5[1] are widely accepted and form the basis for many international actions. Climate change featured strongly in the September 2021 General Assembly of the United Nations. Climate discussion will continue when global leaders meet at the UN Biodiversity Conference (COP15), virtually in October 2021, and physically in April 2022 in Kunming, China. Leaders will convene at UN Climate Change Conference (COP26) in October 2021 in Glasgow, UK.

Correspondence: Jayaindra Fernando

E-mail: jayaindraf@gmail.com

(iD) https://orcid.org/0000-0001-8011-8380

Received: 21-10-2021 Accepted: 26-11-2021

DOI: http://doi.org/10.4038/sljs.v39i3.8916
Impact of health care services on climate change

The interaction between healthcare and climate change is well summarized by Lenzen et al in the Lancet Planet Health[5] who state that, "although the health impacts of pollution and environmental change are well recognized, the environmental impacts of health care have received less attention". The paper concludes that $1-5 \%$ of the global environmental impact is caused by health care provision. This is made up by $4.4 \%$ of greenhouse gases, $2.8 \%$ of particulate matter, $3 \cdot 4 \%$ of $\mathrm{NOx}$, and $3.6 \%$ of $\mathrm{SO} 2$. Other published data indicate $10 \%$ of greenhouse gases in the US [6] are produced by the health care sector.

\section{Impact of surgery on climate change}

Initially the connection between surgery and climate change was not apparent or ignored by the surgical community. In a groundbreaking event, a consensus conference held in 2011 between the Association of Surgeons of Great Britain and Ireland (ASGBI) and Royal College of Surgeons in Ireland (RCSI), concluded in a Consensus Statement On CostEffective And Sustainable Surgery[7] in May 2012. In its introduction, John MacFie, President, ASGBI says "as far as we are aware this is the first attempt by surgeons to collectively address the issue of environmental change". The role of the surgeon is summarized by Eilis McGovern, President, RCSI who said "at first glance, the relationship between surgical practice and climate change might not be obvious. However, there is now ample data to show that health service delivery is a major source of carbon pollution. It is timely, therefore, for surgeons to consider how we might adapt our practice in a way which reduces the surgical carbon footprint and, at the same time, maximizes cost-effectiveness [7]".

Operating theaters are 3-6 more energy intensive than the rest of the hospital 8. Modern surgery is dependent on increased use of energy devises, supporting machinery including imaging devises and robotics, single use consumable instruments, advanced implants, and large operating theater suites, and patient transport systems including fixed wing and rotary wing aircraft. The evidence supporting the hypothesis that these changes have a higher climate cost must be examined. 
Woods et al showed that robotically assisted laparoscopy had a larger carbon footprint compared to laparoscopy and laparotomy in a series of 150 procedures[9]. Siu et al who completed a systematic review of reusable versus disposable laparoscopic instruments: costs and safety, noted a paucity of comparative studies and inconclusive evidence[10]. Authors concluded that further research is needed to address the issue taking into consideration wider environment and financial cost benefits. Guetter et al who reviewed green operating theaters too found an absence of comparative studies[11]. Authors found many opportunities for research and application of green technology in the field. Research has shown that the Carbon footprint, and by implication the climate cost of each surgery is dependent on the type of surgery, duration of surgery, consumables, equipment used, type of theater, type of power supply, and modes of transport involved[12].

A paucity of research papers prevents establishment of a clear verdict on the climate cost of surgery. Of the available evidence, some studies indicate increased climate cost with surgical procedures involving more equipment as in minimal invasive methods and robotics. Other studies are inconclusive as they were not properly structured. Much of the climate cost surgery is through the supply chain as well as running the operating theaters[8]. Both areas can be adapted to more ecofriendly systems. Although it was trendy and convenient to use disposable consumables it may be time to return to reusable consumables which are showing evidence of a lower climate cost[8]. The research and resolution of the climate question is, and should be, of prime relevance to surgeons. When assessing the efficacy of any surgical method, its climate cost too should be factored in.

\section{Mitigation and reversal of climate change}

A country like Sri Lanka, which yearns to move its surgical practice and services to global excellence, will embrace new technology modern science has to offer. This may lead to a higher climate cost in the short term. The global need to mitigate climate change should not stifle advancement of surgery in Sri Lanka. Modes of climate change mitigation must be found to compensate for the higher costs of expansion of surgery. Scientists have identified a rational approach to mitigation of climate change through the AR5 - section on mitigation[13]. This document is due for an update when the full AR6 report is released by the IPCC in 2022.

\section{Conclusion}

Evidence shows that global health care services contribute to the greenhouse gas emissions and other forms of pollution leading to climate change. A significant part of this may be through provision of surgical services. It is relevant that surgeons quantify this contribution and identify modes of mitigation. Many global industries have changed in a bid to reduce the climate cost. Field of surgery is not exempt from this need for change[7]. For change to be universally successful, adaptations need to be at multiple levels including personal and domestic, individual practice, institution and community, national and international. Surgeons by training are expected to be pragmatic and adaptable. This quality could be a key in climate change mitigation in future surgery.

All authors disclose no conflict of interest. The study was conducted in accordance with the ethical standards of the relevant institutional or national ethics committee and the Helsinki Declaration of 1975, as revised in 2000 .

\section{References}

1. R.K. Pachauri and L.A. Meyer (eds.) IPCC: Climate Change 2014: Synthesis Report. Contribution of Working Groups I, II and III to the Fifth Assessment Report of the Intergovernmental Panel on Climate Change. IPCC, Geneva, Switzerland; 2014.

2. The BMJ [Internet]. Full list of authors and signatories to climate emergency editorial September 2021 [cited 2021 Oct 9] Available from https://www.bmj.com/content/full-list-authors-andsignatories-climate-emergency-editorial-september-2021

3. The BMJ [Internet]. Call for emergency action to limit global temperature increases, restore biodiversity, and protect health. BMJ 2021;374:n1734. [cited 2021 Oct 9] Available from https://www.bmj.com/content/374/bmj.n1734

4. Climate Change: The IPCC 1990 and 1992 Assessments. Intergovernmental Panel on Climate Change 1992

5. Manfred Lenzen, Arunima Malik, Mengyu Li, Jacob Fry, Helga Weisz, Peter-Paul Pichler, et al. The environmental footprint of health care: a global assessment. Lancet Planet Health. 2020 Jul;4(7):e271-e279. doi: 10.1016/S2542-5196(20)30121-2

6. Matthew J Eckelman, Jodi Sherman. Environmental Impacts of the U.S. Health Care System and Effects on Public Health. PLoS One. 2016 Jun 9;11(6):e0157014. doi: 10.1371/journal.pone.0157014. eCollection 2016.

7. Association of Surgeons of Great Britain \& Ireland [Internet]. Cost-Effective Surgery: A Consensus Statement [cited 2021 Oct 9] Available from

https://www.asgbi.org.uk/userfiles/file/consensus/asgbi_ consensus_statement_on_cost-effective_surgery.pdf

8. Andrea J MacNeill, Robert Lillywhite, Carl J Brown. The impact of surgery on global climate: a carbon footprinting study of operating theatres in three health systems. Lancet Planet Health. 2017 Dec;1(9):e381-e388. doi: 10.1016/S2542-5196(17)301626. Epub 2017 Dec 8.

9. Demetrius L Woods, Thomas McAndrew , Nicole Nevadunsky, June Y Hou, Gary Goldberg, Dennis Yi-Shin Kuo, et al. Carbon footprint of robotically-assisted laparoscopy, laparoscopy and laparotomy: a comparison. Int J Med Robot . 2015 Dec;11(4):406-12. doi: 10.1002/rcs.1640. Epub 2015 Feb 22. 
10.Joey Siu, Andrew G Hill, Andrew D MacCormick. Systematic review of reusable versus disposable laparoscopic instruments: costs and safety. ANZ J Surg 2017 Jan;87(1-2):28-33. doi: 10.1111/ans. 13856. Epub 2016 Nov 23.

11.Camila R Guetter, Barbara J Williams, Eliza Slama, Amanda Arrington, Marion C Henry, Mecker G Möller, et al. Greening the operating room. Am J Surg. 2018 Oct;216(4):683-688. doi: 10.1016/j.amjsurg.2018.07.021. Epub 2018 Jul 19.
12.Chantelle Rizan, Ingeborg Steinbach, Rosamond Nicholson, Rob Lillywhite, Malcolm Reed, Mahmood F Bhutta. The Carbon Footprint of Surgical Operations: A Systematic Review. Ann Surg. 2020 Dec;272(6):986-995.

doi: 10.1097/SLA.0000000000003951.

13.Climate Change: Mitigation of Climate Change. Working Group III Contribution to the Fifth Assessment Report of the Intergovernmental Panel on Climate Change 2014 